\title{
Giving to Africa and Perceptions of Poverty
}

\author{
Alvin Etang, David Fielding and Stephen Knowles \\ Department of Economics, University of Otago
}

Acknowledgements:

We are extremely grateful to Aaron Lowen, Paul Newnham, Maroš Servátka and Steven Tucker for their many useful comments on our experimental design, and to Corey Allan for valuable research assistance work. We are also grateful to participants at the Faith and Development workshop held at the University of Otago in August 2010, for their insightful comments. We are grateful to the University of Otago for funding this research.

Address for Correspondence:

Stephen Knowles

Department of Economics

University of Otago

PO Box 56

Dunedin 9054

NEW ZEALAND

Phone: ++64 34798350

Fax: ++64 34798174

Email: stephen.knowles@otago.ac.nz 


\begin{abstract}
We conduct a simple experiment in which student participants are invited to give some of the money that they have earned to an international development charity. In different treatments, participants are given different information about the country in which the donation will be spent. The information on the country includes the country's income per capita and, in some treatments, different possible reasons as to why the country is poor. We find that experimental behaviour depends largely on the characteristics of the participant rather than on the treatment. The most important characteristics are the participant's intended major subject, level of happiness and the frequency of religious activity.
\end{abstract}

JEL classification: A13, C91, D64,

Key words: Generosity, Charitable Donations, Altruism, Dictator Game 


\section{Giving to Africa and Perceptions of Poverty}

\section{Introduction}

What motivates people to give money to international development charities? Are people more inclined to give more generously the poorer is the country in which the money will be spent? Does it matter to potential donors why the recipient country is poor? To what extent do individual characteristics, such as gender, the frequency of religious activity, and individual attitudes towards poverty, society and the economy affect donations? This paper seeks to analyse all of these questions in the context of a Dictator Game experiment.

We recruited 131 participants from the student population at the University of Otago in New Zealand to take part in a survey on their perceptions of, and attitudes towards, poverty, society and the economy. Participants had been told they would be paid $20 \mathrm{NZ}$ Dollars $^{1}$ for taking part in the survey, which was also used to collect demographic data on the participants. Once the survey was completed, participants were invited to donate some, or all, of their \$20 payment, if they wished, to World Vision, and were told that any money they chose to donate would be doubled by the researchers. Each participant was provided with information about one of two different countries in which the money would be spent, one of which had an income per capita almost double that of the other. Different participants were given different pieces of information about why the country might be poor (either that it is landlocked, making it difficult to trade with the rest of the world, or that it is politically unstable), which might affect their perceptions about how unfortunate the country was and how effective their donation might be.

We find that, conditional on demographic characteristics, neither the information about the country nor attitudes reported in the survey affect the amount given. However,

\footnotetext{
${ }^{1}$ At the time of the experiment, one NZ Dollar was worth approximately 0.7 US Dollars.
} 
certain demographic characteristics are strongly correlated with the level of generosity; these include the student's subject choice, their participation in religious activities and their reported level of happiness. The next section surveys the literature relevant to our experimental design and results. The results are presented in sections 3 and 4 and section 5 concludes.

\section{Literature Review}

\subsection{Giving and information about recipients in Dictator Games}

Our experiment is a version of the Dictator Game, in which participants are given a sum of money and then have the opportunity to transfer some, or all, of the money to another player. If the recipient is a charity, rather than another player, the Dictator Game can be used to test hypotheses regarding charitable giving. The Dictator Game has been used, for example, to test whether people will give more to charity when their donation is matched dollar for dollar or when the donor gets a rebate of $50 \%$ of their donation. With rational agents, these two treatments should be equivalent, but typically more money is donated in Dictator Games when there is a matching donation. Key papers in this literature include Eckel and Grossman (2003) and Davis (2006).

Our experimental design uses different treatments providing different information on the level of income per capita in the country where the money will be spent, and alternative explanations as to why the country is poor. We are interested in whether this information influences generosity. To our knowledge, there is no experimental evidence on the impact of such information on the size of donations to international charities. ${ }^{2}$ However, three existing

\footnotetext{
${ }^{2}$ There is a non-experimental literature which analyses why some countries receive more foreign aid than others. With a few exceptions (such as Feeney and Clarke, 2007), this literature focuses on aid from official sources (i.e. bilateral and multilateral aid), rather from private individuals via NGOs. Key papers in this literature include Burnside and Dollar (2000) and Alesina and Dollar (2000). It is a common finding in this
} 
Dictator Game studies (Brañas-Garza, 2006; Fong and Luttmer, 2009; Small et al., 2007) are particularly relevant to our research, because they use treatments similar to ours but without varying the level of income per capita, or providing explanations as to why the country is poor, across treatments.

Small et al. (2007) focus on motives for giving money to an international development charity operating in Africa. Their Dictator Game is used to explore whether people give more when presented with personal information about an "identifiable victim", rather than statistical information about the magnitude of the problem of poverty in Africa. Having been paid $\$ 5$ for completing a survey, participants were handed a letter containing information about poverty in Africa, and inviting them to donate part of their $\$ 5$ to Save the Children. In the first treatment, participants were given statistical information about the problems of starvation in Africa, and told that this was caused by food shortages resulting from a lack of rainfall. In a second treatment, participants were given a picture of a young girl from Africa and a brief description of her, noting that she faced the threat of starvation and that participant's donations would change her life for the better. In a third treatment, participants were provided with both the statistical information and the picture and description. Donations were highest with the second treatment and lowest with the first. The authors' interpretation of this result is that people give more when they can picture the individual recipient; providing statistical information just creates a perception that the problem of poverty is too overwhelming for anything to be done.

Fong and Luttmer (2009) explore whether donations to two local charities in the US depend on perceptions of the worthiness of the recipients. Their study was carried out online. Participants saw photographs of charity recipients, and heard an audio tape with information about the charity. Different treatments varied the information about the charities and their literature that poorer and more democratic countries generally receive more aid. There is also evidence that former colonies and countries with smaller populations receive more aid. 
recipients, in order to give different impressions about their worthiness. A subsequent survey was designed to elicit participants' perceptions about worthiness. Moreover, some participants were shown photographs of mainly black recipients, and others photographs of mainly white recipients. On average, participants rated their own racial group as more worthy, but did not give more to them. However, more money was given in treatments designed to create impressions of greater worthiness.

Brañas-Garza (2006) explores whether the amount given to overseas charities by students at two Spanish universities depends on being told the money will go to poor people, and on information about what the money will be used for. In the no information treatment, each participant was given three 5-Euro notes and told that he/she could divide these between himself/herself and three other people; no information about the recipients was provided. In the poverty treatment, each participant was told that the recipients were poor communities in undeveloped countries and that "this amount of money can be very useful in these countries". In the medicines treatment, participants were given the same information as in the poverty treatment, and also told that the money would be used to buy medicines. In the no information treatment the mean donation was $€ 1.50$. This increased to $€ 9$ for the poverty treatment and to $€ 12$ for the medicines treatment. Providing information about the recipients, especially drawing attention to their poverty, increases donations in the Dictator Game.

It has been shown that giving responds both to emotive material about recipients, and to factual information about their identity and the use to which the money will be put. We add to this literature by exploring the effect of more specific information about the level of poverty and its causes (whether the country is landlocked or politically unstable) using a between-subjects design described in section 3. That is, we analyse whether potential donors are interested in exactly how poor is the country in which the money will be spent, and 
alternative reasons for why the country is poor. $^{3}$ Providing a reason for the recipient country's poverty, especially if the reason given is beyond the country's control (e.g. being landlocked) may increase donations. Being poor due to political instability, on the other hand, may be viewed as something avoidable, and hence less worthy of financial support. Participants may also consider that their donation is less likely to be effective in a politically unstable country. Alternatively, it may be that participants simply either want to give money to an international development charity or they do not, and are not particularly interested in the exact level of income per capita, nor why the country is poor. It was noted in footnote 2 that there is evidence that governments and multilateral donors favour giving aid to poorer countries, and that aid allocations depend on the individual characteristics of the recipient country. It remains to be seen whether the same is true for individual private donors.

We also control for the demographic characteristics of the participants, including the subjects they plan to major in at university, their frequency of religious activity and their level of happiness. In order to put this part of our experimental design in context, we briefly review the literature on participant characteristics and Dictator game donations.

\subsection{Giving and information about participants}

Our study controls for the intended major subject studied by each participant. There is already a large literature on the correlations between subjects studied and the level of generosity, with a focus on Economics majors compared with others. The results are very mixed. For example, Frey and Meier (2005) and Yezer et al. (1996) present evidence indicating that Economics majors are significantly more generous than majors in many other

\footnotetext{
${ }^{3}$ Note that although Small et al. (2007) did, in their first treatment, provide information on the reasons for food shortages, our approach differs from theirs in that we test the effect of providing alternative reasons in different treatments as to why the country might be poor.
} 
subject areas, including business disciplines. However, Carter and Irons (1991) find that Economics majors are significantly less likely to propose egalitarian shares in an Ultimatum Game, and Frank et al. (1993) find that Economics professors report significantly less generosity in charitable giving than professors in other subjects. There is a large body of evidence on either side, but one point of agreement, when experiments involve students from different years, is that the study of Economics is associated with a selection effect rather than a treatment effect. The decision to study Economics is often associated with significantly more or significantly less generosity, but conditional on this decision, learning more Economics makes no difference. Such a selection effect is likely to depend on the alternatives to Economics in the university providing the student sample. Variations in the range of subject choice may explain variations in experimental outcomes.

Our student participants were recruited from lectures in the first semester of the first year, so we are also likely to be observing selection effects rather than treatment effects. Given the mixed results in the existing literature, we have no strong prior about the correlations between generosity and subject choice in our sample. However, it may be relevant that at the university providing our sample of students, there are many alternatives to Economics that are relevant to commerce and the professions, including Law, Medicine and Accounting. At our university, students whose choice of subject is career-driven have several alternatives to Economics, many of which are explicitly vocational, so our Economics majors are more likely to behave like majors in science and arts subjects.

Our study controls for whether the participant regularly engages in religious activities. Results from the existing literature on religion and experimental behaviour are also mixed (Anderson et al., 2010; Eckel and Grossman, 2004; Fehr et al., 2003; Ruffle and Sosis, 2007; Tan, 2006; Tan and Vogel, 2008). Religious activity is sometimes associated with greater generosity, but certainly not always: no clear pattern emerges from studies in different parts 
of the world. This may reflect some heterogeneity in the social attitudes associated with religious activity across cultures and countries, even within the West. To our knowledge, ours is the first study of this kind in Australasia, so we have no priors about the association that we will find.

One unambiguous result that does emerge in the literature is that happier people are significantly more generous. Examples of this result include Charness and Grosskopf (2001) and Konow and Earley (2008). It will therefore be important to control for the level of selfreported happiness in our experimental design.

\section{Experimental Method and Protocol}

We recruited participants from three first-year classes in Economics, Philosophy and Politics to take part in the research. ${ }^{4}$ (Therefore, our sample is drawn not from the whole student population, but from a subset of those students taking first year papers in the main social science subjects at the university.) We made a brief announcement about the research project at the start of class. Students were told that if they chose to take part in the research, they would be given an evening, time and venue at which they would be asked to complete a survey on their perceptions and attitudes to poverty, society and the economy, and to take part in a short experiment on economic decision making. They were told that they would be paid \$20 for participating, and that they would be giving up no more than 50 minutes of their time. All students in these three classes were then sent an email repeating this information, and asking them to email one of the researchers if they wished to take part. To ensure that our sample was relatively homogenous, we stated that only students who were aged 18-20 and had lived in New Zealand for at least ten years were able to participate. ${ }^{5}$

\footnotetext{
${ }^{4}$ None of the researchers had taught on any of these classes.

${ }^{5}$ We were concerned that older students and international students (who had been in New Zealand for only a short time) might behave differently to other students. We could have controlled for this by including questions
} 
Having students complete a survey gave us a reason for paying the participants \$20. An alternative would have been to give them $\$ 20$ for no effort, and then ask if they wanted to give some of it back to World Vision. However, participants are likely to have thought of such a payment as a windfall gain. By letting students know in advance that they would be paid $\$ 20$ for taking part in a survey, our hope was that they would view this as earned money. This would more closely mimic a real world situation in which people are asked to donate their own earned income to charity. Previous research (for example, Cherry et al. 2002; Cherry and Shogren, 2008) has shown that experimental participants are likely to be less generous with earned money (for example, payment for performance on a GMAT test) than with windfall gains. The survey also provides us with information on individual characteristics that are likely to affect the amount given. This is especially important given the between subjects nature of our experimental design.

The experiments took place over three consecutive evenings in two different rooms at the university. 161 students had indicated they would take part in the research, but ultimately 131 turned up to take part. We therefore had about 20 participants per room per session. Before the students arrived, a white envelope and pen were placed on each desk. The white envelope contained their \$20 payment, which was made up of one \$10 note, one \$5 note, two $\$ 2$ coins and one \$1 coin. ${ }^{6}$ Once all participants were seated, they were handed a copy of the survey.

The survey, which appears as Appendix 1 of the paper, included a number of questions about attitudes to poverty, society and the economy, and a number of demographic questions. Papers documenting the characteristics that might be associated with participant generosity include Schlegelmilch et al. (1997) and Todd and Lawson (1999). In the light of

about age and nationality in the survey, but the relatively small number of mature and minority students meant that such questions would have jeopardised participant anonymity.

${ }^{6}$ In New Zealand the smallest denomination note is the $\$ 5$ note. 
the literature discussed above, the most important demographic questions in our survey are as follows.

(i) 'All things considered, would you say you are generally happy?'

(ii) 'How frequently do you take part in organised religious activities?' (The responses were coded according to whether the participant indicated participation at least once a week.)

(iii) A question eliciting the participant's intended major degree subject. Given the lectures at which the experiments were advertised, there were reasonably large numbers of participants studying the following major subjects: Accounting, Economics (including Finance), Management / Marketing / Tourism / International Business (four separate but closely related majors, which from now on we call 'Management'), PPE (the Philosophy, Politics and Economics joint major), and Psychology. Most of the remaining participants were studying some other arts subject, such as Film Studies, Geography, History, or Music; these were coded as a single category. The final category comprises the handful of participants who did not disclose which major subject they intended to study.

Other questions in the survey elicited information about the participants' gender, whether they followed the world news frequently, and whether they were a member of some club or society. (The groups were coded as sporting clubs, cultural clubs, charitable clubs and others.) The attitudinal questions, listed in Appendix 1, required the participants to indicate on a 10-point scale the extent to which they agreed with statements such as 'the Government has a moral obligation to redistribute income and wealth from the rich to the poor' and 'Competition is good'. Participants were given 10 minutes to complete the survey. Once everyone had completed the survey, each participant was handed a brown envelope and a 
green envelope and were asked to place their completed survey in the brown envelope, but not to seal the envelope.

Participants were then told that we were about to conduct a short exercise related to charitable giving. We invited them to donate some, or all, of their \$20 payment to World Vision and told them that World Vision would use the money to expand education opportunities in an African country described on the sheet of paper inside the green envelope. We deliberately did not name the country, since we wanted to make sure the only information they had about the country was what we chose to provide. Participants were assured that the country was real, and that the information provided was factually correct. ${ }^{7}$ Participants were told that any money they chose to donate would be matched by us dollar for dollar, and the money then forwarded to World Vision. Participants were then asked to open the green envelope and read the information about the country in which the money would be spent.

Each green envelope contained one of six different treatments. Participants were handed an envelope, and hence assigned to a treatment, at random. In the first treatment, participants were simply told that the country had an income per capita of \$684 per annum, and in the second and third treatments, participants were also given a potential reason why the country was poor. In the second treatment they were told that '[o]ne reason commonly given for the low level of income per capita is that this country is landlocked (meaning it does not have a coastline), which makes it costly to export its goods to overseas markets.' In the third treatment they were told that '[o]ne reason commonly given for the low level of income per capita is that this country has a history of political instability.' Participants might think that political instability, unlike being landlocked, is something the country can control, which might make it less worthy of aid. They may also believe that aid is likely to be less effective in a politically unstable country. The fourth, fifth and sixth treatments were the

\footnotetext{
${ }^{7}$ The lower income country was Niger; the other country was Uganda.
} 
same as the first, second and third, respectively, except that participants were told the income per capita of the country was $\$ 1,165$. Ideally, we would have chosen a country with an income per capita higher than this, to maximise the income gap between the two countries, but World Vision operates only in the poorer African countries. ${ }^{8}$

Having been given the opportunity to read the information sheet, participants were asked to fill in a space on the sheet indicating how much money they wished to donate to World Vision. To check that they understood their donation would be doubled, they were also asked to fill in a space showing how much money World Vision would receive as a result of their donation. It was explained to participants that because of the combination of notes and coins in their white envelope, it was possible for them to donate any whole dollar amount to World Vision. ${ }^{9}$ It was made clear to participants that they were under no obligation to donate any money. Participants were asked to place this form in the brown envelope. Having made their decision, participants were invited one at a time to go behind one of two screens that had been placed at the front of the room. Here they placed their actual cash donation in the brown envelope, and put the brown envelope in a box beside the door as they left the room. Note that by this stage the brown envelope contained their survey form, the information sheet

\footnotetext{
${ }^{8}$ Before opening the green envelope, our students had very similar information to the participants in BrañasGarza's (2006) medicine treatment, insofar as our students knew the money would go to people in a poor country in Africa, and they knew what the money would be used for (education). By further separating them into six treatments, we extend Brañas-Garza by providing different information for each treatment on the precise level of income per capita of the country in which the money would be spent, and why the country is thought to be poor.

${ }^{9}$ One potential concern is that when facing a combination of notes and coins, the participants might have been tempted to donate the smaller denominations (especially the coins) and keep the larger denominations. This could be seen as framing the amount of money participants were likely to give. However, this is not necessarily a major cause for concern. When people are approached in the street and asked to donate to charity, a common response is to donate loose change, so our experimental design mimics what we might expect to happen in reality. Moreover, if deciding how much money to donate, but making a payment by cheque or credit card, people are likely donate a round sum of money; for example, $\$ 10$ is a more common donation than $\$ 9$ or $\$ 11$. Interestingly, a small number of the participants donating $\$ 5$ gave the $\$ 5$ note, rather than the coins.
} 
indicating how much they wished to transfer, and the actual cash donation. Since we had no way of matching participants to envelopes, our methodology ensured a double-blind protocol, protecting the anonymity of the participants.

\section{Experimental Results}

\subsection{Characteristics of the data}

Table 1 presents some summary statistics for the data collected in the experiment. The first line of the table contains information about the distribution of the amount given across all 131 participants. Subsequent lines contain information about the distribution for each of the six treatments and for participants disaggregated by various characteristics: gender, major subject, reported happiness, reported religious activity, interest in world news, and club membership.

The mean amount given across all participants is $\$ 6.04$, but there is a large amount of variation around this mean: 21 participants gave nothing, 17 gave all $\$ 20$, and one participant (an Economics major) gave the $\$ 20$ plus $\$ 1.90$ from his pocket. There are some differences in the means across different treatments, but there is no obvious pattern to these differences. We also find in Section 4.2 below that there are no statistically significant differences across treatments in our multiple regression analysis. It would seem that donations are not greatly influenced by how poor the country is, nor why it is poor. We discuss this finding in more depth in Section 4.2.1, when analysing the regression results. There is also little difference in the shape of the distributions between male and female participants, but there are some striking differences in other dimensions. Across the different subject majors, the mean amount given ranges from \$9.24 (PPE) to \$3.38 (Accounting); no Accounting student sent more than $\$ 10$. All but six participants claimed to be happy, so their distribution is very similar to that for the whole sample, but the mean amount given by the unhappy participants 
is only $\$ 3.50$, and none sent more than $\$ 5$. The religiously active gave more on average than the religiously inactive (\$8.37 versus $\$ 5.43$ ), and there is considerable variation in the means for members of different types of club, with members of sports clubs being the least generous.

The final set of correlates with the amount given comprises the responses to the different survey questions, for which summary statistics are presented in Table 2. Each question elicited a wide range of responses, and for most questions there were some responses at both the minimum and maximum points on the scale. Overall, participants tended to agree with the statements they were shown, with mean responses ranging from 5.24 (that people in general can be trusted) to 8.08 (that competition is good). However, there is a remarkable lack of correlation among the responses to the different questions. The largest correlation coefficient (that income differences provide incentives, that competition is good) is only 0.45 ; across all pairs of responses, the average absolute correlation coefficient is 0.19 . The absence of any strong correlation across questions on closely related topics sheds some doubt on the information contained in the responses; nevertheless, the next section does discuss the results of including survey responses in our regression equation.

\subsection{Regression results}

There are some statistically significant correlations among the participants' characteristics; for example, 'other subject' majors are significantly more likely to be religiously active ( $p=$ 0.04), while Psychology and Economics majors are significantly less likely to follow the world news frequently ( $p=0.06$ in both cases). For this reason, we cannot draw any categorical conclusions from the bivariate correlations between the amount given and the various participant characteristics that we discussed in Section 4.1. Therefore, in this section 
we present regression results that provide us with evidence on the effects of different participant characteristics on the amount given, ceteris paribus.

Model 1 in Table 3 presents the results of a Tobit regression in which the dependent variable is the amount given by the $i^{\text {th }}$ participant $\left(x_{i}\right)$. The explanatory variables $\left(z_{i j}\right)$ comprise the $j$ different treatments and personal characteristics listed in Table $1 .^{10}$ The Tobit model is of the form:

$x_{i}=\max \left(0, \min \left(20, x_{i}^{*}\right)\right)$

$x_{i}^{*}=\beta_{0}+\Sigma_{j} \beta_{j} \cdot z_{i j}+u_{i}$

$u_{i} \sim \mathrm{N}\left(0, \sigma^{2}\right)$

The $\beta$ parameters reported in the table are estimated by Maximum Likelihood. The unobserved latent variable $x_{i}^{*}$ captures the $i^{\text {th }}$ participant's underlying degree of generosity, which may fall below the threshold required to give anything, in which case $x_{i}=0$, or above the threshold required to give everything, in which case $x_{i}=20$. If participants had known beforehand that they would be asked to make a charitable decision, then there would have been no upper censoring: everyone could have brought extra to give. But prior ignorance of the experimental design means that most people’s giving was restricted to $\$ 20$. Note also, that the instructions read out to participants only asked them to consider donating some of their \$20 payment; there was no suggestion that they donate additional money. (The participant who gave the extra $\$ 1.90$ happened by chance to have some change in his pocket; his donation is treated as an observation of $\$ 20 .^{11}$ )

\subsubsection{Treatment effects}

\footnotetext{
${ }^{10}$ We also included dummy variables to test whether there were any experimental session effects. These variables were insignificant, so the variables were excluded from the regressions reported in Table 3.

${ }^{11}$ Nevertheless, the experimenters did double his whole donation when sending money to World Vision.
} 
The table shows that none of the treatments had any significant effect on the amount given. This suggests that participants are sensitive neither to variations in the extent of poverty within the range represented by countries in which charities like World Vision operate, nor to suggested reasons for this poverty. It should be emphasized that the between-subjects design means that no participant was making a choice between the two countries. But when making a choice between their own consumption and charitable giving, the extent of poverty and the reasons for poverty were not significant factors.

As noted above, Small et al. (2007) found that providing statistical information about recipients did not elicit generosity. Brañas-Garza (2006), however, found that subjects gave significantly more when told the recipient was a poor person in a developing country than when they had no information about the recipient. Our results do not contradict this, but suggest that generosity towards a very poor country is no greater than generosity towards another poor country with income per capita almost twice as high. In addition, donations do not depend on any explanations offered for why the country is poor (at least not the explanations offered in our experimental design). Taken together with previous studies, our results suggest that there is little to be gained by charities providing any factual information about the countries where the aid is spent, as long as donors already realise that the country is poor.

\subsubsection{Subject choice}

By contrast with the insignificance of the treatment effects, there are large and statistically significant differences in the effect on the amount given of studying different major subjects. In Table 3, the omitted subject indicator variable is PPE (which is associated with the largest average amount given). There is a negative coefficient on all other subject indicator variables. The coefficients for Economics and Psychology are insignificantly different from zero: 
Economics, Psychology and PPE majors form a group among whom differences in generosity are not statistically significant. However, the coefficients for Accounting and Management majors are much larger in absolute value, and significant at the $5 \%$ level. Ceteris paribus, the average Accounting major can be expected to give $\$ 6.79$ less than the average PPE major, and the average Management major $\$ 6.94$ less. ${ }^{12}$ There is also a particularly large coefficient for those seven participants who do not indicate a major subject: ceteris paribus such participants can be expected to give $\$ 8.69$ less. Finally, the “other subject” majors fall between the two extremes: ceteris paribus, they can be expected to give \$4.86 less than PPE majors on average; this difference is significant at the $10 \%$ level. In our university, Economic students align with those in other social sciences, such as Psychology, and the Economics selection effect is positive, compared with both general arts students and students majoring in business subjects.

\subsubsection{Social and religious activities and happiness}

Two further participant characteristics have a significant effect on the amount given. The first of these is reported happiness. Ceteris paribus, those few participants who claimed not to be happy gave \$5.72 less on average. This negative association between happiness and generosity is consistent with previous experimental results. The second significant effect relates to religious activity. Ceteris paribus, those who reported frequent religious activity gave \$3.51 more on average. Our evidence suggests that in New Zealand religious activity is associated with communitarian social preferences.

Conditional on these characteristics, neither membership of clubs nor self-reported interest in world news has any statistically significant impact on the amount given in our sample. In some cases, this statistical insignificance accompanies a large regression

\footnotetext{
${ }^{12}$ The differences between Economics on the one hand and Accounting and Management on the other are also statistically significant, but only at the $10 \%$ level.
} 
coefficient. For example, those who rarely follow world news gave \$5.28 less on average, but the conditional correlation of interest in the world news with the amount given is not uniform enough to identify any significant effect.

\subsubsection{Survey responses}

When responses to the different survey questions are added to the regression equation, all of them are insignificant at the 5\% level. Only one - the response to 'the Government has a moral obligation to redistribute income and wealth from the rich to the poor' - is significant at the $10 \%$ level. Even this effect should be treated with some caution, since the joint null that none of the survey responses affects the amount given cannot be rejected at any conventional significance level. Nevertheless, we also report a regression equation (Model 2) that includes the responses to 'the Government has a moral obligation to redistribute income and wealth from the rich to the poor' as a regressor. On average, a one point increase in the extent to which the participant agrees with the statement is associated with a donation of an extra 66 cents. Other regression coefficients are very similar to those in Model 1. Overall, responses to the survey do no provide any substantial additional information about the attitudes of the participants.

\section{Summary and Conclusion}

Our results suggest that when giving money to an international development charity, potential donors are not motivated by how poor the developing country is, nor are they influenced by the reasons given for why the country may be poor. Donations are motivated more by the personal characteristics of the potential donor, than by the information provided about the country in which the money will be spent. Combining our findings with those from previous studies, it would seem that international development charities are best to provide emotive 
material about recipients (such as photographs of potential recipients) and information about what donations will be used for, rather than providing factual information about the extent, and causes, of poverty in the recipient country.

Turning to the important personal characteristics that affected donor behaviour, Economics students - along with students of other social science subjects - are typically the most generous, but Accounting and Management students are typically the least generous. This is likely to be a selection effect, and is consistent with the demographic of a university where an Economics degree is more likely to be taken by those with an interest in social issues. As we would expect, happiness has a large, positive and significant effect on generosity, and so, in our sample, does religious activity. Self-reported attitudes to social and economic questions had little significant impact on the level of generosity. 


\section{References}

Alesina, A., Dollar, D., 2000. Who gives foreign aid to whom and why? Journal of Economic Growth 5(1), 33-63.

Anderson, L., Mellor, J., Milyo, J., 2010. Did the Devil make them do it? The effects of religion in public goods and trust games. Kyklos 63(2), 163-175.

Brañas-Garza, P., 2006. Poverty in dictator games: awakening solidarity. Journal of Economic Behavior and Organization 60, 306-320.

Burnside, C., Dollar, D., 2000. Aid, policies and growth. American Economic Review 90(4), 847-868.

Carter, J., Irons, M., 1991. Are economists different, and if so, why? Journal of Economic Perspectives 5, 171-177.

Charness, G., Grosskopf, B., 2001. Relative payoffs and happiness: an experimental study. Journal of Economic Behavior and Organization 45(3), 301-328.

Cherry, T., Frykblom, P., Shogren, J., 2002. Hardnose the dictator. American Economic Review 92(4), 1218-1221.

Cherry, T., Shogren, J., 2008. Self-interest, sympathy and the origins of endowments. Economics Letters 101, 69-72.

Davis, D.D., 2006. Rebate subsidies, matching subsidies and isolation effects. Judgement and Decision Making 1(1), 13-22.

Eckel, C., Grossman, P., 2003. Rebate versus matching: does how we subsidize charitable contributions matter? Journal of Public Economics 87, 681-701.

Eckel, C., Grossman, P., 2004. Giving to secular causes by the religious and nonreligious: an experimental test of the responsiveness of giving to subsidies. Nonprofit and Voluntary Sector Quarterly 33(2), 271-289. 
Feeny, S., Clarke, M., 2007. What determines Australia's response to natural disasters? Australian Economic Review 40(1), 24-36.

Fehr, E., Fischbacher, U., von Rosenbladt, B., Schupp, J., Wagner, G., 2003. A nation-wide laboratory: examining trust and trustworthiness by integrating behavioral experiments into representative surveys. IZA Discussion Paper 715, Bonn, Germany.

Fong, C., Luttmer, E. Do race and fairness matter in generosity? Evidence from a nationally representative charity experiment. Harvard Kennedy School, mimeo.

Frank, R., Gilovich, T., Regan, D., 1993. Does studying economics inhibit cooperation? Journal of Economic Perspectives 7, 159-171.

Frey, B., Meier, S., 2005. Selfish and indoctrinated economists? European Journal of Law and Economics 19, 165-171.

Konow, J., Earley, J., 2008. The hedonistic paradox: is homo economicus happier? Journal of Public Economics 92(1-2), 1-33.

Ruffle, B., Sosis, R., 2007. Does it pay to pray? Evaluating the economic return to religious ritual. B.E. Journal of Economic Analysis and Policy - Contributions 7(1), article 18.

Schlegelmilch, B., Love, A., Diamantopoulos, A., 1997. Responses to different charity appeals: the impact of donor characteristics on the amount of donations. European Journal of Marketing 31(8), 548-560.

Small, D., Loewenstein, G., Slovic, P., 2007. Sympathy and callousness: the impact of deliberative thought on donations to identifiable and statistical victims. Organizational Behaviour and Human Decision Processes 102, 143-153.

Tan, J.H.W., 2006. Religion and social preferences: an experimental study. Economics Letters 90, 60-67.

Tan, J.H.W., Vogel, C., 2008. Religion and trust: an experimental study. Journal of Economic Psychology 29(6), 832-848. 
Todd, S., Lawson, R., 1999. Towards a better understanding of the financial donor: an examination of donor behaviour in terms of value structure and demographics. International Journal of Nonprofit and Voluntary Sector Marketing 4(3), 235-244.

Yezer, A., Goldfarb, R., Poppen, P., 1996. Does studying economics discourage cooperation? Journal of Economic Perspectives 10, 177-186. 


\section{Table 1: Summary Statistics for the Amount Given}

Figures are in NZ Dollars

Whole Sample

mean s.d. $\min . \quad \max . \quad n$

Treatments

Lower income country/ no reason for poverty

$7.17 \quad 7.36$

6.39

0

21.9

131

Lower income country / poor because landlocked

5.82

5.92

4.71

4.56

6.10

6.99

5.48

6.58

6.82

6.90

6.24

7.17

5.86

5.68

8.03

8.47

3.38

2.99

4.45

4.51

7.25

7.89

9.24

7.19

6.50

5.53

2.29

3.59

6.16

6.50

3.50

2.35

8.37

7.37

5.43

6.01

4.38

7.29

6.15

6.35

4.72

5.95

8.89

8.54

6.57

6.58

9.50

7.54

5.68

5.86

0

20

23

0

21.9

23

0

20

21

0

20

21

0

20

21

0

20

22

Member of Cultural club

Member of other club

Not a club member

0

21.9

20

61

0

21.9

70

0

10

26

0

20

13

0

42

20

12

0

20

17

0

20

14

0

10

21.9

7

125

$5 \quad 6$

$21.9 \quad 27$

$20 \quad 104$

$20 \quad 8$

$21.9 \quad 123$

$20 \quad 39$

$21.9 \quad 10$

$20 \quad 7$

$20 \quad 12$

$20 \quad 63$


Table 2: Summary Statistics for Responses to the Survey Questions

$$
\text { (10 = complete agreement; } 0 \text { = complete disagreement })
$$

High earnings are due to hard work mean s.d. $\min . \quad \max . \quad n$

If you look hard enough will find a job

$\begin{array}{lllll}6.15 & 2.13 & 1 & 10 & 131\end{array}$

The Government should redistribute income

$\begin{array}{lllll}6.88 & 2.39 & 1 & 10 & 131\end{array}$

People in general can be trusted

$\begin{array}{lllll}5.31 & 2.35 & 1 & 10 & 131\end{array}$

Income differences provide incentives

$5.24 \quad 2.11$

10

131

Government ownership of industry is good

5.56

5.34

2.30

10

131

People should provide for themselves

7.5

2.13

1

10

131

Competition is good

8.08

1.86

$3 \quad 10$

131

1.60

2

10

131 
Table 3: Determinants of Giving

Model 1

Model 2

Treatments

coeff. std. err. coeff. std. err.

Lower income country / no reason for poverty

3.58

2.61

4.02

2.52

Lower income country / poor because landlocked

1.05

2.33

0.80

2.33

Lower income country / poor because unstable

0.04

2.55

0.38

2.40

Higher income country / poor because landlocked

1.29

2.73

1.58

2.66

Higher income country / poor because unstable

2.61

2.48

2.37

2.44

Participant characteristics

Male

0.19

1.60

0.19

1.58

Economics / Finance major

$-2.60$

3.07

$-3.29$

3.04

Accounting major

Management / Marketing / \&c major

$-6.79 * *$

2.95

$-6.76 * *$

2.86

$-6.94 * * *$

2.53

$-6.26 * *$

2.51

Psychology major

$-2.16$

3.79

$-1.46$

3.86

Other subject major

$-4.86 *$

3.08

$-4.93 *$

3.11

Subject not indicated

$-8.69 * *$

4.07

$-8.43^{* *}$

4.02

Not Happy

$-5.72 * *$

2.73

$-6.14 * *$

2.79

Rarely follows world news

$-5.28$

4.92

$-5.45$

4.82

Member of Sports club

$-1.29$

1.68

$-1.04$

1.65

Member of Charity club

3.09

3.29

2.22

3.08

Member of Cultural club

$-1.39$

3.71

$-0.55$

3.88

Member of other club

4.89

3.27

4.12

3.39

Religiously active

$3.51 *$

1.94

$3.69 *$

1.96

Intercept

8.33

2.66

4.56

3.08

Survey responses

The Government should redistribute income

Joint significance of experimental treatments $(p)$

Joint significance of participant characteristics $(p)$

0.05

0.06

The dependent variable is the amount of money donated. *, **, and *** denote statistical significance at the $10 \%, 5 \%$, and $1 \%$ level, respectively. Standard errors are robust to heteroskedasticity. 


\section{Appendix 1: The Questionnaire}

This questionnaire was completed by participants before they were told that they would be invited to make a charitable donation.

\section{Survey: Poverty, Society and the Economy}

This survey asks questions about your perceptions and attitudes towards poverty, society and the economy more generally, and demographic questions as well. Your responses to the questions will be completely anonymous. No one, including the researchers, will ever know which individuals gave which answers.

Some questions about yourself

1. Gender: Male Female

2. Degree programme: BCom BA

3. Intended major subject (if known)

4. All things considered, would you say you are generally very happy quite happy not very happy not at all happy

5. On average, approximately how many hours per week would you spend reading a newspaper? hours.

6. How often do you follow news from around the world? every day between once and once a month once a week never

7. Are you an active member of any voluntary organisation or club (e.g., sports, craft, social club)? Yes No

If yes, specify what sort of organisation

8. How frequently do you take part in organised religious activities?

more than once a week between once a week and once a month infrequently never 
Some questions about poverty, society and the economy

To what extent do you agree with the following statements? (Circle your answer)

9. People these days are not doing enough to help themselves out of poverty. strongly strongly disagree

$\begin{array}{llllllllll}1 & 2 & 3 & 4 & 5 & 6 & 7 & 8 & 9 & 10\end{array}$

10. Most rich people earn high incomes due to hard work. strongly strongly disagree

$\begin{array}{llllllllll}1 & 2 & 3 & 4 & 5 & 6 & 7 & 8 & 9 & 10\end{array}$

11. Anyone who looks hard enough for a job will find one. strongly strongly disagree agree

$\begin{array}{llllllllll}1 & 2 & 3 & 4 & 5 & 6 & 7 & 8 & 9 & 10\end{array}$

12. The government has a moral obligation to redistribute income and wealth from the rich to the poor.

strongly strongly

disagree

$\begin{array}{llllllllll}1 & 2 & 3 & 4 & 5 & 6 & 7 & 8 & 9 & 10\end{array}$

13. Generally speaking, most people can be trusted.

strongly

strongly disagree

10

23

4

5

14. We need large income differences as incentives for individual effort. strongly disagree

$\begin{array}{llllllllll}1 & 2 & 3 & 4 & 5 & 6 & 7 & 8 & 9 & 10\end{array}$
strongly agree

15. Government ownership of industry is a good thing. strongly disagree

$\begin{array}{llllllllll}1 & 2 & 3 & 4 & 5 & 6 & 7 & 8 & 9 & 10\end{array}$

16. People should take responsibility to provide for themselves.

$\begin{array}{ccccccccccc}\begin{array}{c}\text { strongly } \\ \text { disagree }\end{array} & & & & & & & & & & \begin{array}{c}\text { strongly } \\ \text { agree }\end{array} \\ 1 & 2 & 3 & 4 & 5 & 6 & 7 & 8 & 9 & 10\end{array}$

17. Competition is good. It stimulates people to work hard and develop new ideas. strongly strongly disagree

$\begin{array}{llllllllll}1 & 2 & 3 & 4 & 5 & 6 & 7 & 8 & 9 & 10\end{array}$

